\title{
MODELAGEM DO DESEMPENHO DA EXTRAÇÃO DE MADEIRA PELO "FORWARDER"1
}

Elton da Silva Leite ${ }^{2}$, Haroldo Carlos Fernandes ${ }^{3}$, Luciano José Minette ${ }^{4}$, Amaury Paulo de Souza ${ }^{5}$, Hélio Garcia Leite ${ }^{5}$ e Ilvânio Luiz Guedes ${ }^{6}$

\begin{abstract}
RESUMO - Compreender como os parâmetros condições operacionais e da floresta influenciam na extração florestal, visa reduzir custos, regularizar a produção e oferecer melhores condições de trabalho. Objetivou-se com o presente trabalho modelar as tendências do ciclo operacional, da produtividade e do custo de produção na extração de madeira com o forwarder, variando o sentido de extração em aclive e declive. O forwarder foi avaliado em relação aos fatores das variáveis de declividade do terreno de até $36^{\circ}$, volume por árvores de 0,132 a $0,423 \mathrm{~m}^{3}$ e da distância de extração de até $500 \mathrm{~m}$. Foi utilizado o estudo dos tempos e movimentos para avaliar o processo produtivo e modelar a produtividade e o custo de produção. Os melhores resultados do ciclo operacional da máquina foram registrados nas menores distâncias, maiores volumes e menores declividade do terreno, o que implicou em maior produtividade e menor custo de produção. A máquina proporcionou maior capacidade de extração de madeira, operando no deslocamento carregado em declive, sendo, em média, 20\% maior que em aclive.
\end{abstract}

Palavras-chave: Produtividade; Custo; Produção.

\section{MODELING OF THE PERFORMANCE OF WOOD EXTRACTION MADE BY "FORWARDER"}

\begin{abstract}
Understand how the parameters operational conditions and forest conditions influence in the forest extraction aiming to reduce costs, regulate the production and offer better working conditions. This study aimed to model the trends of operating cycle, productivity and production cost in wood extraction with the forwarder, varying the direction of the extraction in acclivity and declivity. Forwarder was evaluated as for the variables factor of slope of the terrain of up to 36 , volume ranging from 0.132 to $0.423 \mathrm{~m}^{3} \mathrm{per}$ tree and the distance from extraction of up to $500 \mathrm{~m}$. The study of time and movements was used to evaluate production process and model productivity and production cost. The best results of operational cycle of the machine were recorded in the smaller distances, bigger volumes and smaller declivities in the land, which resulted in a higher productivity and lower production cost. The machine provided greater ability in wood extraction, operating in the displacement loaded in declivity, 20\% being, on average, higher than acclivity.
\end{abstract}

Keywords: Productivity; Cost; Production.

\footnotetext{
${ }^{1}$ Recebido em 10.07.2012 aceito para publicação em 04.07.2014.

${ }^{2}$ Centro de Ciências Agrárias, Ambientais e Biológicas, Universidade Federal do Recôncavo da Bahia, Brasil. Email:<elton@ufrb.edu.br>.

${ }^{3}$ Departamento de Engenharia Agrícola, Universidade Federal de Viçosa, Brasil. E-mail: <haroldo@ufv.br>.

${ }^{4}$ Departamento de Engenharia Elétrica e de Produção, Universidade Federal de Viçosa, Brasil. E-mail: <minette@ufv.br>.

${ }^{5}$ Departamento de Engenharia Florestal, Universidade Federal de Viçosa, Brasil. E-mail: <amaury@ufv.br>e <hgleite@gmail.com> .

${ }^{6}$ Celulose Nipo-brasileira S/A - Cenibra, Brasil. E-mail: <ilvanio.guedes@cenibra.com.br>.
} 


\section{INTRODUÇÃO}

No Brasil, a área de floresta plantada, para fins comerciais, foi de 6,6 milhões de hectares em 2012 (ABRAF, 2013), em detrimento de crescentes demandas por produtos de base florestal. Além disso, a crescente expansão de áreas florestais está associada às características de qualidade e precocidade genética, solo, clima e mecanização, gerando grandes retornos financeiros, principalmente pela maximização da produtividade na colheita florestal.

A colheita florestal destaca-se pela sua maior importância econômica na produção de madeira, tornando a atividade um processo contínuo de melhorias das condições de operação dos sistemas de colheita.

O sistema de toras curtas apresenta no cenário brasileiro o de maior destaque na colheita e preconiza por utilizar equipamentos de alta tecnologia, como o transportador forwarder, usado na extração de madeira, com vantagem de altos rendimentos operacionais.

O desempenho do transportador pode ser afetado por diversas variáveis, destacando-se as condições operacionais e da floresta. Segundo Jiroušek et al. (2007), os volumes médios de madeira das árvores e as distâncias de extração são fatores cruciais nas operações de extração de madeira. Lima e Leite (2008) completaram dizendo que a declividade do terreno é uma das variáveis operacionais mais importantes, podendo tornar inviável o tráfego de máquinas.

O desempenho das máquinas é avaliado através de estudos dos tempos e movimentos (motion-time study). O estudo permite a organização do trabalho, a produtividade e o custo por unidade produzida em relação aos fatores relevantes na colheita (SEIXAS et al., 2004), visando ao planejamento e à otimização da operação de colheita florestal (ANDRADE, 1998 apud SIMÕES et al., 2010).

Na extração florestal, métodos que utilizam cabos demandam altos custos de produção, além de apresentarem elevado esforço físico e periculosidade. A introdução do forwarder na extração de áreas acidentadas visa reduzir custos, regularizar a produção e oferecer melhores condições de trabalho, proporcionando ao trabalhador maior conforto e segurança, o que o mantém protegido contra as intempéries.

Revista Árvore, Viçosa-MG, v.38, n.5, p.879-887, 2014
Objetivou-se com este trabalho modelar as atividades do ciclo operacional, a produtividade e o custo de produção em operação de extração de madeira com o trator autocarregável forwarder, em relação aos fatores das variáveis de declividade do terreno, volume de madeira das árvores e distância de extração, variando o sentido de extração em aclive e declive.

\section{MATERIAL E MÉTODOS}

A avaliação foi realizada no Estado de Minas Gerais, na região do Rio Doce, em áreas plantadas de clones híbridos de Eucalyptus grandis com Eucalyptus urophylla, tendo como característica genética a alta produtividade em regime de primeira rotação, com espaçamento de 3,00 m entre plantas por 3,33 m entre filas, com idade de 6,0 a 9,5 anos, com linhas de plantio direcionadas perpendiculares às curvas de nível, “morro acima”.

Na região de estudo predomina o solo do tipo Latossolo Vermelho-Amarelo. O clima é classificado como Aw, clima tropical com estação seca de Inverno (KÖPPEN, 1948). A precipitação média anual de 1.350 $\mathrm{mm}$, com temperatura média anual de $25,2{ }^{\circ} \mathrm{C}$ e umidade relativa média do ar anual de 65,2\% (CARNEIRO et al., 2003).

Este estudo consistiu da avaliação da etapa de extração em 190 unidades experimentais relacionadas aos fatores de declividade do terreno em até $36^{\circ}$, pelo volume de madeira por árvore sem casca de 0,1320 a 0,4255 m³ e pela distância de extração de até 500 m. Cada unidade experimental foi composta por quatro linhas com 25 árvores em cada, totalizando 100 indivíduos na área.

Empregou-se o sistema de colheita de toras curtas (cut-to-length), com traçamento no tamanho em torno de $6 \mathrm{~m}$ e a constituição dos feixes das toras formados pelo harvester. Foram avaliadas as atividades no período de três turnos diários operacionais, com 8 h em cada, durante março de 2010 a junho de 2011.

O forwarder utilizado foi o da marca John Deere, modelo 1710D, motor John Deere 6081 diesel, com potência de 215 hp (160,3 kW), razão transmissão hidrostática, capacidade de carga de 17 t, garra Hultdins, modelo 360S, capacidade de 0,36 $\mathrm{m}^{2}$ de área, ligado à lança hidráulica, comandos acionados por joystick, tração 8 x 8 de pneus BPAF (baixa pressão e alta flutuação), com esteiras metálicas unindo os pares dianteiros e traseiros. 
A coleta de dados foi efetuada pela amostragem sistemática, sendo computados o total de 398 ciclos operacionais; desses, 247 ciclos na operação em declive e 151 em aclive, distribuídos em função da declividade e do volume por árvore, valores superiores ao estimado por Barnes (1968 citado por MINETTE et al., 2004; SIMÕES et al., 2011), equação 1.

$$
n \geq \frac{t C V}{E^{2}}
$$

em que $\mathrm{n}$ = número mínimo de ciclos necessários; $\mathrm{t}$ = valor de $\mathrm{t}$ para o nível de probabilidade desejado e (n-1) graus de liberdade; CV = coeficiente de variação, (\%); e E = erro de amostragem admissível a 95\% de probabilidade.

No estudo de tempos e movimentos, foram registrados os tempos gastos nas jornadas das atividades do ciclo operacional do forwarder, com a utilização do método de estudo contínuo, conforme metodologia adotada por Barnes (1968), Moreira (2000) e Lopes et al. (2009). As atividades do ciclo operacional foram carregamento, descarregamento, deslocamento com e sem carga, limpeza e interrupções, de acordo com a direção de deslocamento (aclive e declive), sendo:

- A atividade de carregamento refere-se ao tempo decorrido para recolher a madeira na unidade experimental e ao autocarregamento até a acomodação das toras no interior da caixa de carga da máquina.

- A atividade de descarregamento compreende o período em que se retira a madeira acomodada na caixa de carga até o posicionamento da pilha à margem da estrada.

- O deslocamento sem carga iniciou-se com o forwarder vazio e terminou com o início do autocarregamento.

- O deslocamento com carga iniciou com o forwarder carregado e terminou com o início do autodescarregamento.

- A operação de limpeza refere-se ao tempo decorrido para a retirada de obstáculos e resíduos no local de formação das pilhas.

- As interrupções são referentes às pausas técnicas e pessoais.

- O sentido declive refere-se à extração da madeira realizada em direção morro abaixo (descendo), ou seja, a parcela encontra-se na altitude superior da estrada, realizando o deslocamento vazio em aclive.
- O sentido aclive refere-se à extração da madeira realizada em direção morro acima (subindo), ou seja, a parcela encontra-se na altitude inferior da estrada, realizando o deslocamento vazio em declive.

Para determinação das velocidades do sistema de extração da madeira de dentro da área colhida, computou-se a distância (percurso) da máquina, em metros; e o tempo, em segundos, obtendo-se a velocidade. O percurso foi obtido com o auxílio de um distanciômetro da marca Bushnell, modelo Yardage Pro 600, tendo como referência a cabine da máquina, determinando as distâncias das viagens com carga e sem carga.

A produtividade das máquinas foi determinada em metros cúbicos de madeira sem casca por horas efetivamente trabalhadas $\left(\mathrm{m}^{3} \mathrm{~h}^{-1}\right)$, com o uso da equação 2. O volume de madeira foi determinado pelo inventário em cada unidade experimental antes das operações de corte.

$$
P=\frac{V}{H e}
$$

em que: $\mathrm{P}=$ produtividade $\left(\mathrm{m}^{3} \mathrm{~h}^{-1}\right) ; \mathrm{V}=$ volume da unidade amostral $\left(\mathrm{m}^{3}\right)$; e He $=$ horas efetivas de trabalho (h).

Nas unidades amostrais com declividades acima de $25^{\circ}$, foi utilizado um trator agrícola de pneus, marca Massey Fergusson, modelo 297, motor diesel, marca Perkins, modelo 1006-6, com seis cilindros, potência nominal de $120 \mathrm{cv}(79,47 \mathrm{~kW})$, que acionava com a utilização da tomada de potência (TDP) um guincho da marca TMO modelo G, com capacidade para guinchamento de 33 toneladas, com cabo de aço de 5/8" 6 x 25 ou 6 x 19, resistência à tração entre 1.770$2.160 \mathrm{~N} \mathrm{~mm}^{-1}$, carga mínima de ruptura $18.700 \mathrm{kgf}$ $(183,38 \mathrm{kN})$, usado para auxiliar no avanço do forwarder.

O engate do cabo do guincho foi realizado pela caixa de carga do forwarder. Com auxílio de uma célula de carga de 100 kN, determinou-se a potência máxima requerida do cabo de aço, conforme a equação 3 .

$$
\mathrm{Pr}=\mathrm{Fm} \mathrm{Vm}
$$

em que $\mathrm{Pr}=$ potência de tração requerida $(\mathrm{kW})$; $\mathrm{Fm}$ = força de tração média na barra de tração $(\mathrm{kN})$; e $\mathrm{Vm}=$ velocidade média de deslocamento $\left(\mathrm{m} \mathrm{s}^{-1}\right)$.

A análise de custos da extração de madeira foi obtida pelo somatório do custo fixo e do custo variável. Os custos fixos e os custos variáveis foram expressos 
em dólares por hora efetiva de trabalho, segundo a metodologia usada por Simões e Fenner (2010) e Leite et al. (2013), adaptada de American Society of Agricultural Engineers (ASAE, 2001). Utilizou-se a taxa de câmbio de dólar igual a R\$,802, cotação de 11 de janeiro de 2012.

Os dados foram inicialmente submetidos a ajustes de modelos de superfície de resposta, selecionando os modelos mais adequados para quantificar o comportamento das atividades do ciclo operacional e comprovando ser precisos e de fácil aplicação. As observações discrepantes (outliers) foram excluídas com o auxílio do teste de Bonfferoni (WEISBERG, 2005). Verificou-se o pressuposto de normalidade e homogeneidade do modelo ajustado pelo teste de ShapiroWilk (ROYSTON, 1982). As análises foram processadas utilizando o software R (R DEVELOPMENT CORE TEAM, 2012).

\section{RESULTADOS}

\subsection{Estudos de tempos e movimentos}

Na Tabela 1 está compilada a constituição percentual média dos elementos do ciclo operacional do forwarder, em função da direção de extração de madeira em declive e aclive, para uma distância média de extração de $150 \mathrm{~m}$. Observa-se, nessa tabela, diferença no deslocamento com carga, e isso se deve ao fato de a declividade reduzir a velocidade média de locomoção em virtude da razão de redução de percurso (patinagem) e instabilidade e do risco de tombamento da máquina.

O ciclo operacional total médio do forwarder foi de 27,96 e 28,16 min (1.677,6 e 1.689,6 seg), nas direções em declive e aclive, respectivamente.
A variação da distância de extração de 150 m para 300 m acarretou aumento de 33\% no tempo de operação da máquina, evidenciando a necessidade de planejar melhor o ponto ótimo correspondente à distância média de extração com relação ao custo da malha viária.

A atividade que obteve maior representatividade foi o carregamento da máquina, seguido do descarregamento; juntos, corresponderam a $66 \%$ do tempo total do ciclo operacional do forwarder. O volume médio de madeira sem casca acondicionada na caixa de carga foi, em média, de 13,42 $\mathrm{m}^{3}$.

Na Tabela 2, encontra-se compilada a modelagem dos tempos das atividades de extração de madeira pelo forwarder na operação de aclive e declive, verificado o comportamento na Figura 1. À medida que aumenta a declividade do terreno e a distância de extração eleva o tempo da atividade de deslocamento, observa-se que a declividade apresenta maior impacto no sentido de extração em aclive. À medida que aumenta a declividade do terreno e diminui o volume por árvore, há incremento do tempo com a atividade de carregamento, e a declividade afeta os movimentos da lança hidráulica, necessitando de maior atenção nos movimentos dessa lança e reduzindo o volume de madeira na garra, e os maiores volumes dos toretes de madeira favorecem o ajuste da carga na garra.

A análise de regressão efetuada entre os tempos de descarregamento e limpeza não foi significativa, não ocorrendo correspondências funcionais entre as direções de extração, a declividade e o volume por árvore.

\subsection{Produtividade}

Nas equações 4 e 5, verificam-se os resultados da modelagem da capacidade de extração de madeira pelo trator forwarder, no sentido de aclive e de declive,

Tabela 1 - Valores médios dos tempos das atividades do ciclo operacional do forwarder no sentido de extração em declive e em aclive, para o percurso de $150 \mathrm{~m}$.

Table 1 - Mean values of time in the activities of the operational cycle of the forwarder in the direction of extraction in declivity and acclivity for $150 \mathrm{~m}$.

\begin{tabular}{|c|c|c|c|c|}
\hline \multirow[t]{2}{*}{ Atividade do ciclo operacional } & \multicolumn{2}{|c|}{ Declive } & \multicolumn{2}{|c|}{ Aclive } \\
\hline & Velocidade $\left(\mathrm{m} \mathrm{s}^{-1}\right)$ & Tempo(s) & Velocidade $\left(\mathrm{m} \mathrm{s}^{-1}\right)$ & Tempo(s) \\
\hline Deslocamento sem carga & 0,593 & 253,15 & 0,640 & 234,38 \\
\hline Carregamento & - & 667,03 & - & 664,23 \\
\hline Deslocamento com carga & 0,545 & 275,22 & 0,458 & 327,56 \\
\hline Limpeza & - & 12,48 & - & 12,13 \\
\hline Descarregamento & - & 401,48 & - & 395,49 \\
\hline Total & - & $1.609,36$ & - & 1633,78 \\
\hline
\end{tabular}

Revista Árvore, Viçosa-MG, v.38, n.5, p.879-887, 2014 
Tabela 2 - Modelos do estudo de tempos e movimentos do ciclo operacional do forwarder, em função do sentido de extração. Table 2 - Models of the study of time and movement of the operation cycle of the forwarder, according to the extraction direction.

\begin{tabular}{cccc}
\hline Deslocamento & Direção & Modelos & $\mathrm{r}^{2}$ \\
\hline Com carga & Aclive & Tcca $=-35,178^{* * *}+5,974 * * * d+1,316^{* * *} L$ & 0,850 \\
& Declive & Tccd $=-9,345^{*}+5,611 * * * d+1,751 * * * L$ & 0,903 \\
Sem carga & Aclive & Tsca $=-9,886^{* * *}+0,671 * * * d+1,588 * * * L$ & 0,968 \\
& Declive & Tscd=-6,040-1,457***d-1,457***L & 0,974 \\
Carregamento & Aclive & Tcara $=606,467 * * *+20,998 d^{* * *}-820,690 * * V$ & 0,842 \\
& Declive & Tcara $=449,903 * * *+14831 * * *$ d- $159,198 * V$ & 0,834 \\
\hline
\end{tabular}

$\mathrm{d}$ = declividade; $\mathrm{L}=$ deslocamento; e $\mathrm{v}=$ volume por árvore.

$d=$ slope $; L=$ displacement ; and $v=$ volume per tree.

em razão da declividade do terreno, em graus, e da distância de extração, em m. Na Figura 3 estão compilados os resultados da modelagem.

$$
\begin{aligned}
& \text { Pfa }=52.478 * * *-0.923 * * * \mathrm{~d}-0.051 * * * \mathrm{~L} \\
& \mathrm{r}^{2} \text { ajustado }=0,8927 \\
& \mathrm{p}-\text { valor: }<2,2 \mathrm{e}^{-16} \\
& \text { Pfd }=50.111 * * *-0.543 * * * \mathrm{~d}-0.029 * * * \mathrm{~L} \\
& \mathrm{r}^{2} \text { ajustado }=0,8201 \\
& \mathrm{p}-\text { valor: }<2,2 \mathrm{e}^{-16}
\end{aligned}
$$

em que Pfa = produtividade do forwarder em aclive $\left(\mathrm{m}^{3} \mathrm{~h}^{-1}\right)$; Pfd = produtividade do forwarder em declive $\left(\mathrm{m}^{3} \mathrm{~h}^{-1}\right) ; \mathrm{d}=\operatorname{declividade}\left({ }^{\circ}\right)$; e $\mathrm{L}=\operatorname{deslocamento}(\mathrm{m})$.

Constata-se que, à medida que a declividade do terreno aumentou e a distância de extração também aumentou, a produtividade do forwarder caiu substancialmente. Na extração em aclive, a variável de declividade obteve a influência de $75 \%$ e, para a variável distância de extração, foi de $25 \%$, na produtividade do forwarder. Entretanto, observou-se, no sentido do declive, que a declividade explicou o comportamento da produtividade em 55\%, e o impacto da variável distância de extração foi de $45 \%$.

A potência de tração requerida para permitir a adequação do sistema de guincho, para auxiliar na tração das máquinas, deve ser de 47,16kW (64,12 cv), constatada pela maior velocidade atingida nas operações com o uso do guincho. Recomenda-se a adaptação de um sistema de guincho com velocidades similares da máquina, para permitir intensificar o corte mecanizado nas áreas consideradas restritivas ao tracionamento.

\subsection{Custos}

O custo operacional do forwarder John Deere, modelo 1710D, foi de US\$125,24 por h efetivamente trabalhada, adotando-se uma taxa real de juros de $12 \%$ a.a., eficiência operacional da máquina de 85\%. Desse total, foram: US\$26,15 h ${ }^{-1}$ (20,88\%) de custos fixos e US\$ 99,09 $\mathrm{h}^{-1}(79,12 \%)$ de custos variáveis, sendo os valores dos componentes dos custos apresentados na Figura 2.

O custo operacional do conjunto trator agrícola e guincho foi de US\$46.07 $\mathrm{h}^{-1}$, adotando-se uma taxa real de juros de $12 \%$ a.a., eficiência operacional da máquina de $80 \%$, operando 1.000 h ao ano, vida útil de 15 anos e custo de aquisição de R\$160.000,00. Recomenda-se adaptar o guincho na caixa de carga do forwarder, para evitar o uso adicional de outra máquina na operação e reduzir custos operacionais.

Os custos de produção do forwarder encontram-se compilados pelas equações 6 e 7, em função da distância de extração e da declividade do terreno. Na Figura 3, apresentam-se os resultados das modelagens do custo de produção. Caso optar pelo uso conjunto trator agrícolaguincho, haverá aumento do custo de produção na extração com o forwarder em 36,78 \%, nas declividades de 25 a $36^{\circ}$.

$$
\begin{aligned}
& \text { CPfa }=1,9144^{* * *}-0,8113^{* * *} \times \mathrm{d}+0,00833^{* * *} \times \mathrm{L} \\
& \mathrm{r}^{2} \text { ajustado }=0,8636 \\
& \mathrm{p} \text {-valor: }<2,2 \mathrm{e}-16 \\
& \mathrm{CPfd}=2,1586^{* * *}-0,0512^{* * *} \times \mathrm{d}+0,00324 * * * \times \mathrm{L} \\
& \mathrm{r}^{2} \text { ajustado }=0,7865 \\
& \text { p-valor: }<2,2 \mathrm{e}-16
\end{aligned}
$$

Revista Árvore, Viçosa-MG, v.38, n.5, p.879-887, 2014 
em que CPfa = custo de produção do forwarder em aclive (US\$ $\mathrm{m}^{-3}$ ); CPfd = custo de produção do forwarder em declive (US $\$ \mathrm{~m}^{-3}$ ); $\mathrm{d}=\operatorname{declividade}\left(^{\circ}\right.$ ); e $\mathrm{L}=$ distância de extração (m).

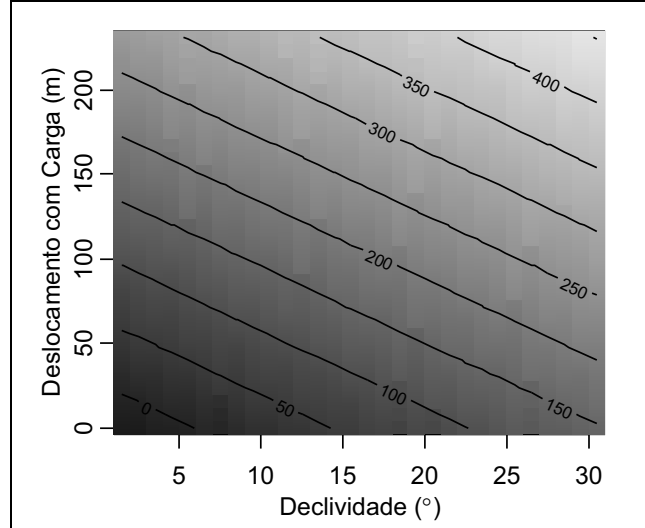

Tempo de deslocamento com carga (s)

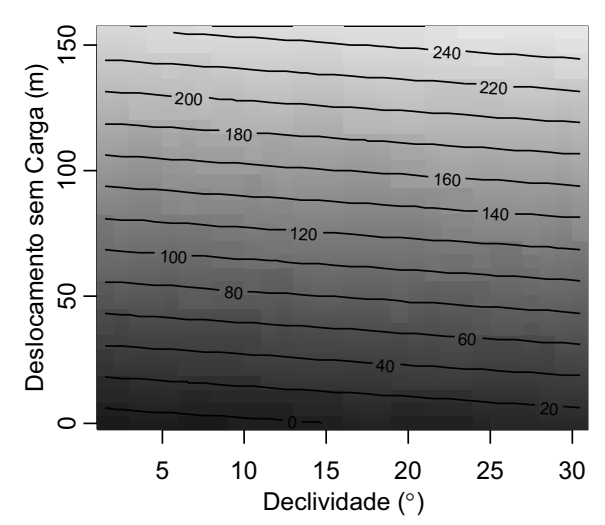

Tempo de deslocamento sem carga (s)

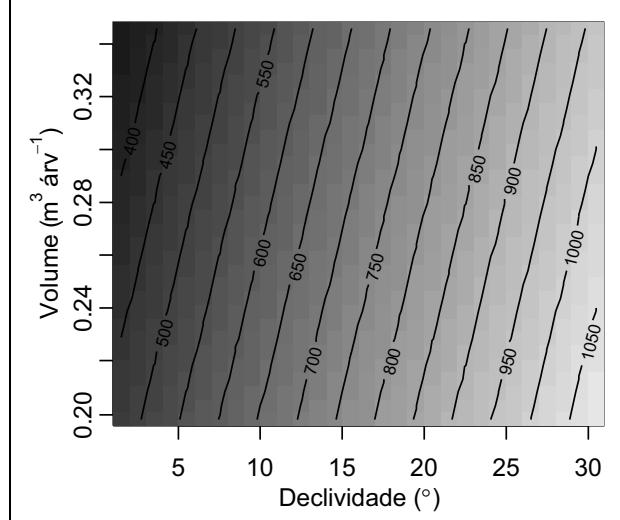

Tempo de carregamento (s)

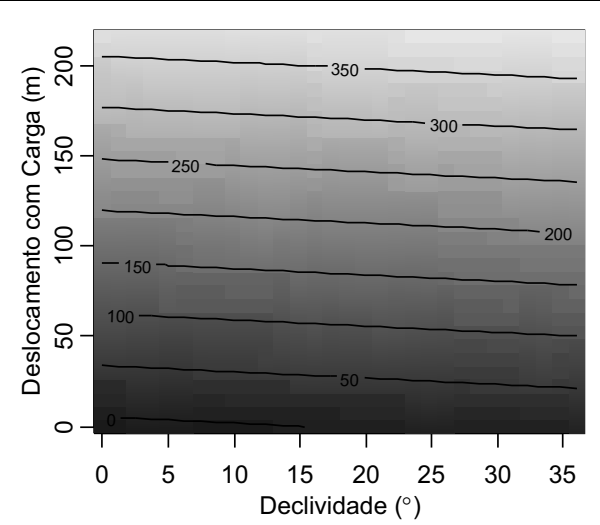

Tempo de deslocamento com carga (s)

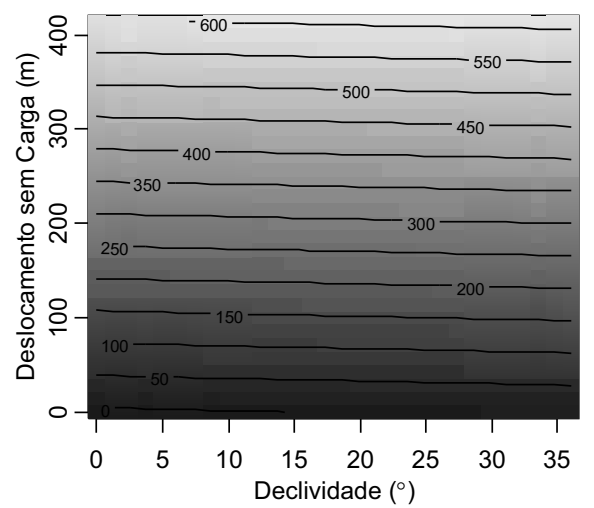

Tempo de deslocamento sem carga (s)

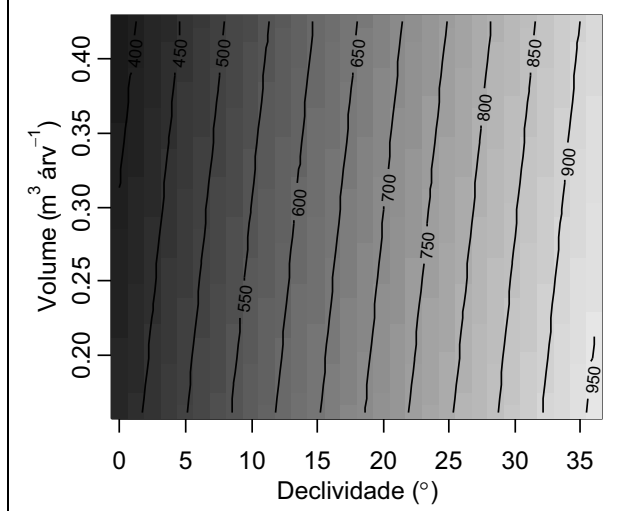

Tempo de carregamento (s)

Figura 1 - Modelagem dos tempos, em segundos, das atividades do ciclo operacional do trator forwarder, em função da direção de extração em aclive (a) e em declive (b).

Figure 1 - Modeling of time, in seconds, of the activity in operational cycle of the tractor forwarder, according to the direction of the extraction in acclivity (a) and declivity (b).

Revista Árvore, Viçosa-MG, v.38, n.5, p.879-887, 2014 


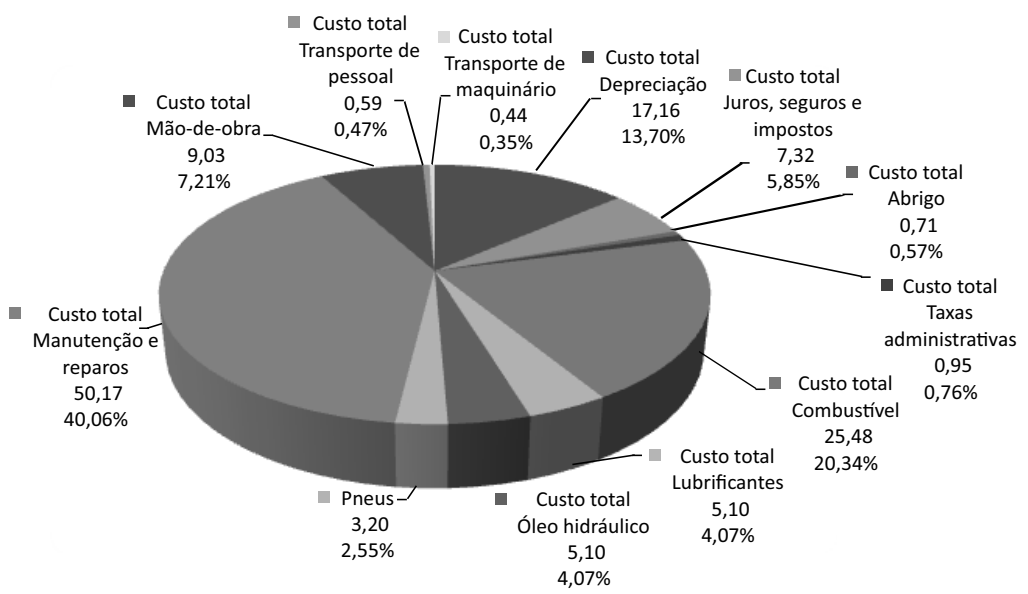

Figura 2 - Componentes do custo operacional do forwarder John Deere 1710D, em dólares por hora efetiva trabalhada

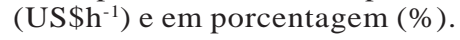

Figure 2-Operational cost components of the forwarder John Deere $1710 D$, in dollars per effectively worked hour (US $\left.\$ h^{-1}\right)$ and in percentage $(\%)$.

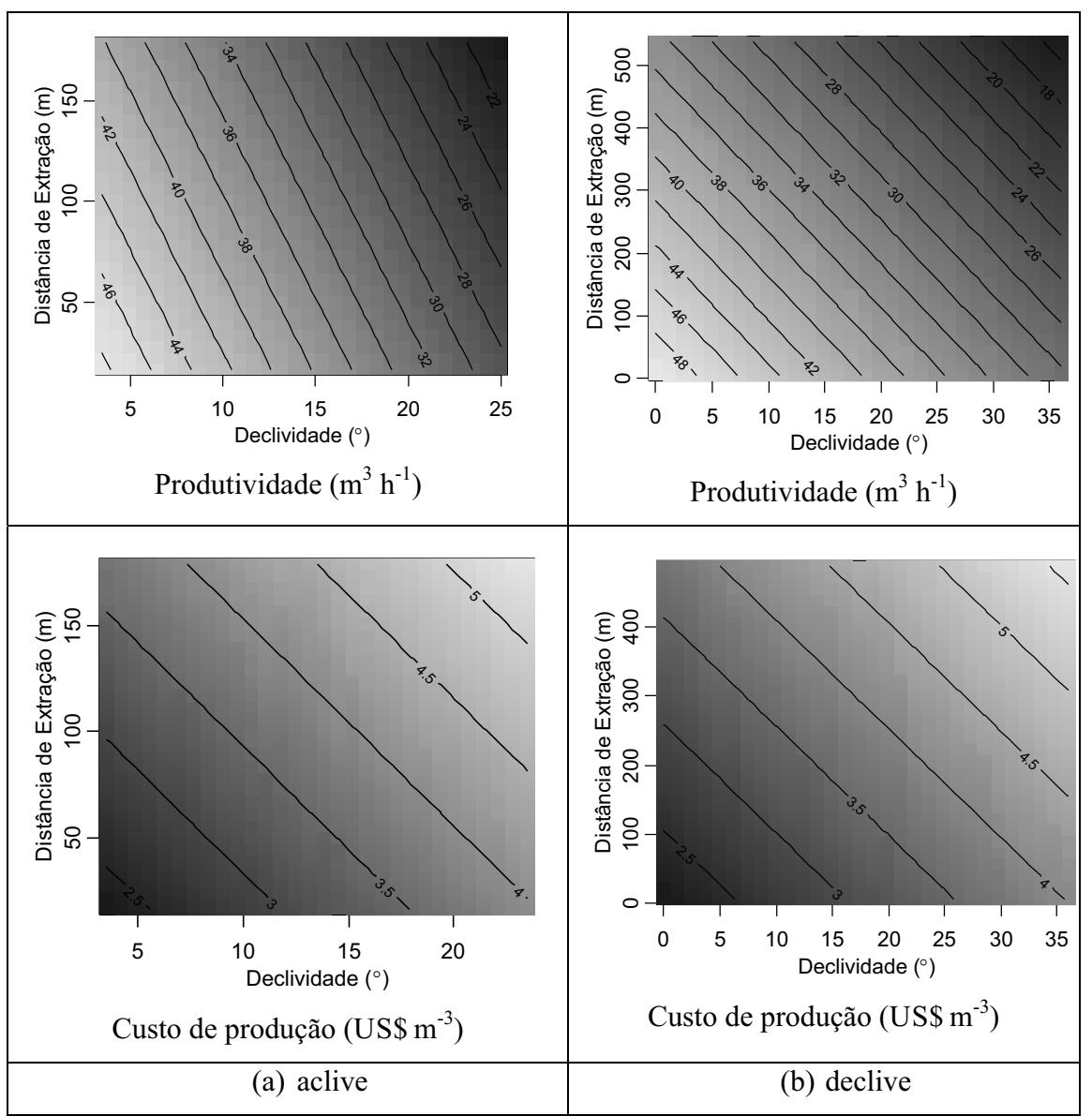

Figura 3 - Produtividade e custo de produção do forwarder no sentido de extração em aclive e em declive.

Figure 3 - Productivity and cost of production of the forwarder in the direction of the extraction on acclivity and declivity. 


\section{DISCUSSÃO}

As velocidades do forwarder encontradas neste trabalho são consideradas baixas quando comparadas com as obtidas no trabalho de Bantel (2006). Isso é explicado pela maior declividade do terreno deste trabalho, pois esse autor avaliou o forwarder Valmet 890.2 apenas em locais planos, encontrando 2,45 m $\mathrm{s}^{-1}\left(8,82 \mathrm{~km} \mathrm{~h}^{-1}\right)$ e $2,31 \mathrm{~m} \mathrm{~s}^{-1}\left(8,31 \mathrm{~km} \mathrm{~h}^{-1}\right)$ para os deslocamentos sem carga e com carga. Os tempos do ciclo operacional do forwarder obtidos pelo referido autor totalizaram 29,16 min; desses, 9,37\% (176,4 s) no deslocamento sem carga; 43,02\% (810,0 s) no carregamento; 8,03\% (151,2 s) no deslocamento com carga; 39,58\% (745,2 s) no descarregamento, na extração de madeira de eucalipto de $6 \mathrm{~m}$ no espaçamento 3,00 m x 2,00 m, com volume por árvore de $0,19 \mathrm{~m}^{3} \mathrm{arv}^{1}$ e distância média de $150 \mathrm{~m}$.

Minette et al. (2004) avaliaram o forwarder da marca Timberjack, modelo 1210B, na extração de madeira de eucalipto em uma distância média de 132 m, com toras de $6 \mathrm{~m}$ de comprimento. Esses autores encontraram a seguinte porcentagem de 7,38\% no deslocamento sem carga; 53,28\% no carregamento; 5,96\% no deslocamento com carga; e 28,33\% no descarregamento, completando o ciclo operacional em 16 min. O tempo menor do ciclo operacional deveu-se, principalmente, ao fato de o forwarder utilizado pelos autores apresentar menor capacidade de transporte, tornando o ciclo operacional mais curto, pois a maior parte do tempo a máquina encontrava-se carregando ou descarregando.

Makkonen (1989) confirmou que a produtividade do forwarder aumenta com a diminuição da distância de extração, em que encontrou $24 \mathrm{~m}^{3} \mathrm{~h}^{-1}$, para uma distância de extração de $360 \mathrm{~m}$ e 31,6 $\mathrm{m}^{3} \mathrm{~h}^{-1}$ para uma distância de $170 \mathrm{~m}$, representando queda de $24 \%$ na produtividade. Entretanto, os valores de produtividade neste estudo foram maiores que o encontrado por esse autor, em virtude, principalmente, das características de maior dimensão da caixa de carga, potência, alcance da grua e da área de atuação da garra da máquina deste estudo.

A mesma situação ocorre quando se comparam os resultados desta pesquisa com os de Jiroušek et al. (2007), avaliando a produtividade de extração de madeira com o forwarder em condições de 0,1 a 1,0 $\mathrm{m}^{3}$ de madeira árvore ${ }^{-1}$ e distância de extração variando de 80 a 1.400 m. Neste estudo, foi encontrada uma produtividade inferior às deste estudo, comprovando que forwarder mais robusto apresenta maiores produtividades.

Minette et al. (2004) encontraram as produtividades de 35,47 e 40,15 $\mathrm{m}^{3} \mathrm{~h}^{-1}$, para distâncias de 122 e $129 \mathrm{~m}$, custo operacional de US $\$ 60,70 \mathrm{~h}^{-1}$ e custo de produção de US\$1,74 $\mathrm{m}^{-3}$. Os valores de custo operacional são muito inferiores aos aqui encontrados, o que acarretou na redução do custo de produção em razão, possivelmente, de esses autores terem trabalhado com menor índice de declividade do terreno e diferentes máquinas.

Simões e Fenner (2010), avaliando o forwarder Valmet 890.2/6WD, obtiveram o custo operacional de $35,83 \%$ para os custos fixos e $64,17 \%$ para os custos variáveis, o custo de produção de US $\$ 2,90 \mathrm{~m}^{-3}$ e uma produtividade de $40 \mathrm{~m}^{3} \mathrm{~h}^{-1}$, aproximando dos dados deste trabalho.

\section{CONCLUSÕES}

- A modelagem quantificou a influência da declividade do terreno, da distância de deslocamento e do volume de madeira por árvore no estudo de tempos e movimentos do ciclo operacional, na produtividade e custo de produção do forwarder.

- Os melhores resultados do ciclo operacional da máquina foram registrados nas menores distâncias, maiores volumes e menores declividades do terreno, o que implicou maior produtividade e menor custo de produção.

- O forwarder apresentou maior capacidade de extração de madeira operando no deslocamento carregado em declive, sendo, em média, 20\% maior que em aclive, proporcionando menor custo de produção na extração em declive.

- O custo de produção foi de aproximadamente $37 \%$ para adoção do trator agrícola e guincho para auxiliar a tração em declividade acima de $25^{\circ}$, recomendando-se adotar guincho no forwarder, com vista à redução significativa de custo.

\section{AGRADECIMENTOS}

Ao Conselho Nacional de Desenvolvimento Científico e Tecnológico (CNPq), à Fundação de Amparo à Pesquisa do Estado de Minas Gerais (FAPEMIG) e à Celulose Nipo-Brasileira S. A. (CENIBRA), pelo apoio financeiro e pela oportunidade. 


\section{REFERÊNCIAS}

AMERICAN SOCIETY OF AGRICULTURAL ENGINEERS - ASAE. ASAE standards 2001: machinery, equipment and buildings: operating costs. Ames: 2001. p.164-226.

ASSOCIAÇÃO BRASILEIRA DE PRODUTOS DE FLORESTAL PLANTADAS - ABRAF. Anuário estatístico da ABRAF. 2013 ano base 2012. Brasília: 2013. 149p.

BAntel, C. A. Análise de extração de madeira de eucalipto com forwarder em floresta de primeira e segunda rotação. 2006. 126f. Dissertação (Mestrado em Energia na Agricultura) - Universidade Estadual Paulista, Botucatu, 2006.

CARNEIRO, L. C. et al. Coeficiente de desacoplamento em plantios jovens de eucalipto. São José dos Campos: INPE, 2003. 6p.

JIROUŠEK, R.; KLVAÈ, R.; SKOUPÝ, A. Productivity and costs of the mechanized cut-tolength wood harvesting system in clear-felling operations. Journal of Forest Science, v.53, n.10, p.476-482, 2007.

KOPPEN, W. Climatologia com un estudio de los climas de la tierra. México: Fondo de Cultura Econômica, 1948. 478p.

LEITE, E. S. et al. Modelagem técnica e de custos do harvester no corte de madeira de eucalipto no sistema de toras curtas. Scientia Forestalis, v.41, n.98, p.205-215, 2013.

LIMA, J. S. S.; LEITE, A. M. P. Mecanização. In: MACHADO, C. C. (Org.). Colheita florestal. 2.ed. Viçosa, MG: Universidade Federal de Viçosa, 2008. p.43-65.

LOPES, S. E. et al. Avaliação técnica e econômica de um "skidder" operando em diferentes produtividades e distâncias de extração. Ciência Agrotecnica, v.33, n.6, p.1621-1626, 2009.
MAKKONEN, I. Evaluation of Timberjack 230 8-Ton Forwarder. Pointe-Claire, Quebec: Forestry Engineering Research Institute of Canada, 1989. 8p. (Technical Note TN-140).

MINETTE, L. J. et al. Análise técnica e econômica do forwarder em três subsistemas de colheita de florestas de eucalipto. Revista Árvore, v.28, n.1, p.91-97, 2004.

MOREIRA, F. M. T. Análise técnica e econômica de subsistemas de colheita de madeira de eucalipto em terceira rotação. 2000. 148 f. Dissertação (Mestrado em Ciência Florestal) - Universidade Federal de Viçosa, Viçosa, MG, 2000.

R DEVELOPMENT CORE TEAM. R: A language and environment for statistical computing. 2012. Vienna: R Foundation for Statistical Computing. Disponível em: <http://www.R-project.org>.

Acesso em: 1ํo jan. 2012.

ROYSTON, P. An extension of Shapiro and Wilk's $\mathrm{W}$ test for normality to large samples. Applied Statistics, v.31, p.115-124, 1982.

SEIXAS, F.; BARBOSA, R. F.; RUMMER, R. Tecnologia protege saúde do operador. Madeira, v.14, n.82, p.68-73, 2004.

SIMÕES, D.; FENNER, P. T. Avaliação técnica e econômica do forwarder na extração de madeira em povoamento de eucalipto de primeiro corte. Floresta, v.40, n.4, p.711-720, 2010.

SIMÕES, D.; FENNER, P. T.; ESPERANCINI, M. S. T. Avaliação técnica e econômica da colheita de florestas de eucalipto com harvester. Scientia Forestalis, v.38, n.88, p.611-618, 2010.

SIMÕES, D.; FENNER, P. T.; BANTEL, C. A. Análise operacional e econômica do processamento de madeira de eucalitpo com “hypro” em região montanhosa. Revista Árvore, v.35, n.3, p.505-514, 2011.

WEISBERG, S. Applied linear regression. 3.ed. Hoboken: Wiley, 2005. 